\title{
Molecular Features and Prognostic Factors of Pleomorphic Xanthoastrocytoma: A Collaborative Investigation of the Tohoku Brain Tumor Study Group
}

\author{
Takahiro ONO, ${ }^{1}$ Toshio SASAJIMA, ${ }^{1}$ Hiroaki SHIMIZU, ${ }^{1}$ Manabu NATSUMEDA, ${ }^{2}$ \\ Masayuki KANAMORI, ${ }^{3}$ Kenichiro ASANO, ${ }^{4}$ Takaaki BEPPU, ${ }^{5}$ Kenichiro MATSUdA, ${ }^{6}$ \\ Masahiro ICHIKAWA, ${ }^{7}$ Yukihiko FujII, ${ }^{2}$ Hiroki OHKUMA, ${ }^{4}$ Kuniaki OgasAWARA, ${ }^{5}$ \\ Yukihiko SONODA, ${ }^{6}$ Kiyoshi SAITO, ${ }^{7}$ Sumihito NOBUSAWA, ${ }^{8}$ Yoichi NAKAZATO, ${ }^{9}$ \\ Chifumi KitanaKa, ${ }^{10}$ Takamasa KaYama, ${ }^{11}$ Teiji TominaGA, ${ }^{3}$ \\ and For the Tohoku Brain Tumor Study Group ${ }^{6}$ \\ ${ }^{1}$ Department of Neurosurgery, Akita University Graduate School of Medicine, Akita, \\ Akita, Japan \\ ${ }^{2}$ Department of Neurosurgery, Brain Research Institute, Niigata University, Niigata, Niigata, \\ Japan \\ ${ }^{3}$ Department of Neurosurgery, Tohoku University Graduate School of Medicine, Sendai, \\ Miyagi, Japan \\ ${ }^{4}$ Department of Neurosurgery, Hirosaki University Graduate School of Medicine, Hirosaki, \\ Aomori, Japan \\ ${ }^{5}$ Department of Neurosurgery, Iwate Medical University, Morioka, Iwate, Japan \\ ${ }^{6}$ Department of Neurosurgery, Faculty of Medicine, Yamagata University, Yamagata, \\ Yamagata, Japan \\ ${ }^{7}$ Department of Neurosurgery, Fukushima Medical University, Fukushima, Fukushima Japan \\ ${ }^{8}$ Department of Human Pathology, Gunma University Graduate School of Medicine, \\ Maebashi, Gunma, Japan \\ ${ }^{9}$ Department of Pathology, Hidaka Hospital, Takasaki, Gunma, Japan \\ ${ }^{10}$ Department of Molecular Cancer Science, Yamagata University School of Medicine, \\ Yamagata, Yamagata, Japan \\ ${ }^{11}$ Department of Advanced Medicine, Faculty of Medicine, Yamagata University, Yamagata, \\ Yamagata, Japan
}

\begin{abstract}
Pleomorphic xanthoastrocytoma (PXA) is a rare glial tumor, however, its histological differentiation from high-grade gliomas is often difficult. Molecular characteristics may contribute to a better diagnostic discrimination. Prognostic factors of PXA are also important but few relevant reports have been published. This study investigated the molecular features and prognostic factors of PXAs. Seven university hospitals participated in this study by providing retrospective clinical data and tumor samples of PXA cases between 1993 and 2014. Tumor samples were analyzed for immunohistochemical (IHC) neuronal and glial markers along with Ki67. The status of the BRAF and TERT promoter (TERTp) mutation was also evaluated using the same samples, followed by feature extraction of PXA and survival analyses. In all, 19 primary cases (17 PXA and 2 anaplastic PXA) were included. IHC examination revealed the stable staining of nestin and the close association of synaptophysin to NFP. Of the PXA cases, $57 \%$ had the BRAF mutation and only $7 \%$ had the TERTp mutation. On univariate analysis, age ( $\geq 60$ years), preoperative Karnofsky performance status
\end{abstract}

Received May 12, 2020, Accepted July 1, 2020

Copyright $\odot 2020$ by The Japan Neurosurgical Society This work is licensed under a Creative Commons AttributionNonCommercial-NoDerivatives International License. 
(KPS) $(\leq 80 \%)$, and marked peritumoral edema were significantly associated with progression-free survival (PFS). No independent factor was indicated by the multivariate analysis. In conclusion, PXA was characterized by positive nestin staining and a few TERTp mutations. The neuronal differential marker and BRAF status may help in diagnosis. Patient age, preoperative KPS, and marked perifocal edema were associated with PFS. The present study is limited because of small number of cases and its retrospective nature. Further clinical study is needed.

Keywords: differential diagnosis, neuronal differentiation, pleomorphic xanthoastrocytoma, prognostic factors, TERT promoter mutation

\section{Introduction}

Pleomorphic xanthoastrocytoma (PXA) is a rare glial tumor that comprises $<1 \%$ of all astrocytic neoplasms and is mostly observed in children and young adults. ${ }^{1)}$ PXAs and glioblastomas (GBMs) share a pleomorphic histological appearance, resulting in difficulties for differential diagnoses. ${ }^{2,3)}$ However, most PXAs show better prognosis and are classified as WHO grade II, moreover, PXA may be cured with a complete resection without additional radiochemotherapy. ${ }^{4)}$ Thus, methods of definitive diagnosis using preoperative imaging, and intraoperative rapid and postoperative histological examinations are desired. Several neuronal markers and BRAF mutation are reported to be characteristic of PXAs ${ }^{1,5,6)}$, however, results are not yet conclusive. Better discrimination using other molecular features would help to properly diagnose and treat patients with PXAs.

Some PXAs show malignant histological features and aggressive clinical behavior. BRAF mutation may relate to better prognosis, ${ }^{4,7}$, however, no reliable prognostic factor has yet been established. Considering treatment, the roles of radiotherapy and chemotherapy for PXAs have also not been well defined.

Therefore, the current study investigated molecular features and prognostic factors of PXAs.

\section{Materials and Methods}

\section{Study design}

A retrospective, observational multicenter study by the Tohoku Brain Tumor Study Group including Akita, Hirosaki, Yamagata, Tohoku, and Niigata Universities, together with Iwate and Fukushima Medical Universities. This study was approved by the ethics committee of the above institutions with the approval numbers of 1286, 2016-1047, H27-287, 2015-1-718, 1488, H24-96, 2065, respectively.

\section{Clinical data and human tumor specimens}

Clinical data and tissue samples of a total of 23 primary cases that were initially diagnosed as PXA between 1993 and 2014 in each institute were provided for this study. Clinical information included patient's age, sex, preoperative Karnofsky performance status (KPS), extent of resection, radiotherapy, chemotherapy, progression-free survival (PFS) and overall survival (OS) as listed in Table 1.

Tumor samples from all cases were centrally rereviewed by expert neuropathologists (Yoichi Nakazato, Hidaka Hospital, and Sumihito Nobusawa, Gunma University) prior to further analysis in this study. Only cases diagnosed as PXA based on the previous version of the WHO Classification of Tumors of the Central Nervous System (WHO2007) were included in the present study.

\section{Radiological findings on magnetic resonance imaging}

Tumor location and size, together with peritumoral edema were evaluated on a preoperative magnetic resonance imaging (MRI). The extent of resection was qualitatively classified on a postoperative MRI.

\section{Histology and immunohistochemistry}

Adjacent 4- $\mu$ m-thick sections served for hematoxylin \& eosin (HE) and reticulin-staining, and immunohistochemical (IHC) staining, respectively. IHC staining was performed with the Ventana Benchmark-XT (Roche Diagnostics K.K. Tokyo, Japan) targeting at GFAP $(1: 5000),{ }^{8)}$ S-100 $(1: 10000),{ }^{8)}$ nestin (1:100, Millipore), synaptophysin (1:1, Roche), NFP (1:100, Invitrogen), NeuN (1:2000, Millipore), CD34 (1:1, Roche), IDH1 R132H (1:50, Dianova), and Ki67 (1:1, Roche). For Ki67 analysis, tumor areas with the highest Ki67 labeling were selected, and the images were captured with a microscopic digital camera, then, the labeling index was calculated using the Image-J software. ${ }^{9)}$

\section{DNA extraction and direct DNA sequencing for $B R A F$ and TERT promoter mutations}

DNA was extracted from FFPE tissue sections, as previously described, ${ }^{10,11)}$ and was amplified and sequenced using the primers described previously. ${ }^{12,13)}$ The polymerase chain reaction (PCR) products were 
Table 1 Clinical and radiological characteristics, treatment modalities, and outcomes of patients with PXAs

\begin{tabular}{|c|c|c|c|c|c|c|c|c|c|c|c|c|c|c|}
\hline Case & Sex & Age & Initial symptoms & $\begin{array}{l}\text { Pre-op } \\
\text { KPS }\end{array}$ & Location & $\begin{array}{l}\text { Size } \\
(\mathrm{cm})^{*}\end{array}$ & $\begin{array}{l}\text { Peritumoral } \\
\text { edema }\end{array}$ & $\begin{array}{l}\text { Extent of } \\
\text { resection }\end{array}$ & RT (dose, fr) & ChT & $\begin{array}{l}\text { Central } \\
\text { review }\end{array}$ & $\begin{array}{l}\operatorname{Rec} \\
(\mathrm{mo})\end{array}$ & $\begin{array}{l}\mathrm{F} / \mathrm{U} \\
(\mathrm{mo})\end{array}$ & Outcome \\
\hline 1 & $\mathrm{~F}$ & 7 & NF1 & 100 & $\begin{array}{l}\text { Rt. } \\
\text { frontal }\end{array}$ & 4.0 & None & TR & & & PXA & & 158 & Alive \\
\hline 2 & $\mathrm{~F}$ & 13 & Sensory disorder & 100 & $\begin{array}{l}\text { Rt. } \\
\text { insula }\end{array}$ & 4.0 & Moderate & STR & $\begin{array}{c}\text { SRT } \\
(40 \mathrm{~Gy}, 9 \mathrm{fr})\end{array}$ & & PXA & 113 & 165 & Alive \\
\hline 3 & $\mathrm{~F}$ & 60 & $\begin{array}{l}\text { Motor aphasia, visual field } \\
\text { constriction }\end{array}$ & 90 & $\begin{array}{c}\text { Lt. } \\
\text { temporal }\end{array}$ & 7.7 & Moderate & STR & & & PXA & 12 & 72 & Alive \\
\hline 4 & M & 30 & Sensory disorder & 100 & $\begin{array}{c}\text { Lt. } \\
\text { parietal }\end{array}$ & 7.0 & Moderate & $\mathrm{TR}$ & & & PXA & & 59 & Alive \\
\hline 5 & M & 65 & Gait disorder & 50 & $\begin{array}{c}\text { Lt. } \\
\text { temporal }\end{array}$ & 3.5 & Marked & $\mathrm{TR}$ & Local RT (60 Gy, 30 fr) & $\begin{array}{l}\text { ACNU IFN } \\
\text { TMZ }\end{array}$ & $\mathrm{PXA}^{* *}$ & 7 & 28 & Died \\
\hline 6 & $\mathrm{~F}$ & 59 & $\begin{array}{l}\text { Headache, hemiparesis } \\
\text { (intratumoral hemorrhage) }\end{array}$ & 10 & $\begin{array}{c}\text { Lt. } \\
\text { temporal }\end{array}$ & 2.0 & None & TR & & & PXA & 5 & 38 & Died \\
\hline 7 & M & 18 & Seizure & 90 & $\begin{array}{c}\text { Lt. } \\
\text { temporal }\end{array}$ & 3.5 & Marked & STR & & & PXA & 37 & 96 & Alive \\
\hline 8 & $\mathrm{~F}$ & 20 & Seizure & 90 & $\begin{array}{c}\text { Lt. } \\
\text { parietal }\end{array}$ & 2.3 & Moderate & $\mathrm{TR}$ & & & PXA & & 42 & Alive \\
\hline 9 & $\mathrm{~F}$ & 58 & Seizure & 90 & $\begin{array}{l}\text { Rt. } \\
\text { frontal }\end{array}$ & 5.5 & Moderate & $\mathrm{TR}$ & & & PXA & & 204 & Alive \\
\hline 10 & M & 20 & Seizure & 90 & $\begin{array}{c}\text { Rt. } \\
\text { temporal }\end{array}$ & 2.0 & Moderate & $\mathrm{TR}$ & & & PXA & & 61 & Alive \\
\hline 11 & $\mathrm{~F}$ & 68 & Sensory aphasia & 80 & $\begin{array}{c}\text { Lt. } \\
\text { parietal }\end{array}$ & 6.0 & Marked & STR & Local RT (60 Gy, 30 fr) & & PXA & 6 & 95 & Alive \\
\hline 12 & M & 16 & Seizure & 100 & $\begin{array}{c}\text { Lt. } \\
\text { temporal }\end{array}$ & 4.0 & Moderate & STR & Local RT (50 Gy, 25 fr) & & PXA & & 321 & Alive \\
\hline 13 & $\mathrm{~F}$ & 11 & Seizure & 60 & $\begin{array}{c}\text { Rt. } \\
\text { temporal }\end{array}$ & 6.0 & Moderate & $\mathrm{PR}$ & & PCV & PXA & & 91 & Alive \\
\hline 14 & M & 36 & Headache, nausea & 90 & $\begin{array}{c}\text { 4th } \\
\text { ventricle }\end{array}$ & 2.5 & None & $\mathrm{TR}$ & & & PXA & & 120 & Alive \\
\hline 15 & M & 18 & Seizure & 100 & $\begin{array}{c}\text { Rt. } \\
\text { temporal }\end{array}$ & 4.5 & Marked & $\mathrm{TR}$ & & & PXA & 47 & 89 & Alive \\
\hline 16 & M & 17 & Seizure & 100 & $\begin{array}{c}\text { Rt. } \\
\text { parietal }\end{array}$ & 2.5 & Moderate & TR & & & PXA & & 79 & Alive \\
\hline 17 & $\mathrm{~F}$ & 44 & Seizure & 100 & $\begin{array}{c}\text { Rt. } \\
\text { temporal }\end{array}$ & 8.0 & None & $\mathrm{TR}$ & & & PXA & & 45 & Alive \\
\hline 18 & $\mathrm{~F}$ & 16 & $\begin{array}{c}\text { Headache, nausea, sensory } \\
\text { disorder }\end{array}$ & 90 & $\begin{array}{c}\text { Lt. } \\
\text { parietal }\end{array}$ & 7.0 & Moderate & STR & $\begin{array}{l}\text { Local RT (60 Gy, } 30 \text { fr) } \\
\text { Boost SRT ( } 20 \text { Gy, } 5 \text { fr) }\end{array}$ & TMZ & A-PXA & & 77 & Alive \\
\hline 19 & M & 74 & Seizure & 70 & $\begin{array}{l}\text { Lt. } \\
\text { frontal }\end{array}$ & 3.5 & Moderate & STR & Local RT (60 Gy, 30 fr) & TMZ & A-PXA & 4 & 9 & Died \\
\hline
\end{tabular}

*The longest diameter determined on gadolinium-enhanced T1-weighted magnetic resonance imaging, **local diagnosis was A-PXA. ACNU: nimustine, ChT: chemotherapy, F: female, fr: fraction, F/U: follow-up, IFN: interferon-beta, KPS: Karnofsky performance status, Lt: left, M: male, mo: months, NF1: neurofibromatosis type 1, PCV: procarbazine, lomustine, and vincristine regimen, PR: partial resection, Pre-op: preoperative, PXAs: pleomorphic xanthoastrocytomas, Rec: recurrence, Rt: right, RT: radiotherapy, SRT: stereotactic radiotherapy, STR: subtotal resection, TMZ: temozolomide, TR: total resection. 
sequenced on a 3130xl Genetic Analyzer (Applied Biosystems, Foster City, CA, USA) with the Big Dye Terminator v.1.1 Cycle Sequencing Kit (Applied Biosystems). Standard procedures were followed.

\section{Statistical analysis}

In univariate analyses, log-rank tests were performed to assess the prognostic significance between each parameter and clinical outcomes (PFS and OS). For quantitative parameters, the cutoff points showing the lowest $\mathrm{p}$ value were used. Survival curves were generated using the Kaplan-Meier method. Then, the multivariate Cox proportional hazard regression was performed to assess the independence among prognostic factors identified in univariate analyses. $P$ values less than 0.05 were considered significant. All statistical analyses were performed with an EZR (Saitama Medical Center, Jichi Medical University, Saitama, Japan), the graphical user interface for $\mathrm{R}$ (The R Foundation for Statistical Computing, Vienna, Austria). More precisely, the EZR is a modified version of $\mathrm{R}$ commander designed to add statistical functions frequently used in biostatistics. ${ }^{14)}$

\section{Results}

\section{Patient characteristics}

The central re-review found four cases who were later diagnosed with tumors other than PXA (ganglioglioma, anaplastic glioma, GBM, and an insufficient sample for diagnosis, respectively) and these patients were subsequently excluded. The remaining 19 cases were investigated in further analysis.

The patient characteristics, radiological findings, and treatment modalities are listed in Table 1 and summarized in Table 2. Of the 19 cases, $11 \%$ were anaplastic PXA (A-PXA). There were no gender differences in the results. The median age was 20 years.

Almost all cases had epilepsy or focal signs as initial symptoms. One of the cases was associated with neurofibromatosis type 1 , and the lesion in the brain was observed during a general examination. All cases were independent with median preoperative KPS of $90 \%$.

Tumor location was supratentorial in all cases except for one case, and was predominant in the temporal lobe. The median tumor size was as large as $4 \mathrm{~cm}$. Most tumors had mild to moderate peritumoral edema.

Total resection was performed in 11 PXA cases $(58 \%)$. In this regard, one case received radiochemotherapy according to its local diagnosis: A-PXA. In six PXA cases with subtotal or partial removal, three cases received radiotherapy and one case received chemotherapy. Two A-PXA cases received subtotal removal and postoperative radiochemotherapy.
Survival data were available for all cases, and the median follow-up period was 79 months (range: 9-321 months). In 17 patients with PXA, the 5-year and 10-year PFS rates were $63.5 \%$ and $50.8 \%$, respectively. The 5-year and 10-year OS rates were both $88.2 \%$. In two patients with A-PXA, the 5 -year PFS and OS rate were both 50\%. The 10-year PFS and OS were not determinable. In addition, the median PFS and OS were not determinable.

\section{Histology, immunohistochemistry, and gene muta- tion findings}

The histological and molecular data are listed in Table 3 and summarized in Table 4. Histological features of PXA were characterized by prominent pleomorphism with comparatively less mitosis, vascular proliferation, and necrosis. A-PXA tended to present more aggressive histological features.

Considering the immunophenotypes, all 19 cases were positive or focally positive for GFAP, S-100, and nestin. The stainability of nestin was the most stable.

In neuronal markers, synaptophysin and NFP were positive in $11(58 \%)$ and $9(47 \%)$ of the cases, respectively. Of these, eight cases showed statistically significant rates of co-expression of synaptophysin and NFP ( $\mathrm{p}=0.0498$, Fisher's exact test).

All the samples were negative for NeuN, a marker of mature neurons, and IDH1 R132H. CD34 was at least focally positive in nine cases (47\%). The Ki67 index was generally low, except for A-PXA. The $B R A F$ V600E or 599ins T mutations were observed in $8 / 14$ cases $(57 \%)$. The $B R A F$ status of 2 A-PXA was wild-type. The TERT promoter (TERTp) mutation was found in only one case of A-PXA.

\section{Survival analyses}

Univariate analyses for PFS revealed that age $\geq 60$ years (Fig. 1A), preoperative KPS $\leq 80 \%$ (Fig. 1B), and marked peritumoral edema (Fig. 1C) were significant factors associated with tumor recurrence. There was no statistical difference between total resection and subtotal/partial resection (Fig. 1D), and other factors such as tumor size, IHC and mutation status, radiotherapy, and chemotherapy had no prognostic impact for PFS. Multivariate analysis showed no statistically independent prognostic factor: the $\mathrm{p}$ value of each factor was 0.073 for age, 0.285 for preoperative KPS, and 0.328 for peritumoral edema, respectively.

Survival analysis for OS was not applicable because only three cases died during the follow-up period. 
Table 2 Summary of clinical and radiological characteristics, treatment modalities, and outcomes in the present series

\begin{tabular}{|c|c|c|c|}
\hline Clinical characteristics & PXA & A-PXA & All \\
\hline Total number of cases & 17 & 2 & 19 \\
\hline Male, n (\%) & $8(47 \%)$ & $1(50 \%)$ & $9(47 \%)$ \\
\hline Age at diagnosis, median (range) & $20(7-68)$ & $45(16-74)$ & $20(7-74)$ \\
\hline \multicolumn{4}{|l|}{ Initial symptoms, n (\%) } \\
\hline Seizure & $9(53 \%)$ & $1(50 \%)$ & $10(53 \%)$ \\
\hline Focal signs & $7(41 \%)$ & $1(50 \%)$ & $8(42 \%)$ \\
\hline Other & $1(6 \%)$ & 0 & $1(5 \%)$ \\
\hline Preoperative KPS, median (range) & $90 \%(10-100)$ & $80 \%(70-90)$ & $90 \%(10-100)$ \\
\hline \multicolumn{4}{|l|}{ Location, n (\%) } \\
\hline Supratentorial & $16(94 \%)$ & $2(100 \%)$ & $18(95 \%)$ \\
\hline Temporal lobe & $9(53 \%)$ & 0 & $9(47 \%)$ \\
\hline Infratentorial & $1(6 \%)$ & 0 & $1(5 \%)$ \\
\hline Tumor size*, median (range) & $4.0 \mathrm{~cm}(2.0-8.0)$ & $5.3 \mathrm{~cm}(3.5-7.0)$ & $4.0 \mathrm{~cm}(2.0-8.0)$ \\
\hline \multicolumn{4}{|l|}{ Peritumoral edema, n (\%) } \\
\hline Mild to moderate & $13(76 \%)$ & $2(100 \%)$ & $15(79 \%)$ \\
\hline Marked & $4(24 \%)$ & 0 & $4(21 \%)$ \\
\hline \multicolumn{4}{|l|}{ Extent of resection, n (\%) } \\
\hline Total resection & $11(65 \%)$ & 0 & $11(58 \%)$ \\
\hline Subtotal resection & $5(29 \%)$ & $2(100 \%)$ & $7(37 \%)$ \\
\hline Partial resection & $1(6 \%)$ & 0 & $1(5 \%)$ \\
\hline Radiotherapy, n (\%) & $4(24 \%)$ & $2(100 \%)$ & $6(32 \%)$ \\
\hline Local radiotherapy & $3(18 \%)$ & $1(50 \%)$ & $4(21 \%)$ \\
\hline Stereotactic radiotherapy & $1(6 \%)$ & 0 & $1(5 \%)$ \\
\hline Combined & 0 & $1(50 \%)$ & $1(5 \%)$ \\
\hline Chemotherapy, n (\%) & $2(12 \%)$ & $2(100 \%)$ & $4(21 \%)$ \\
\hline Combined with radiotherapy & $1(6 \%)$ & $2(100 \%)$ & $3(16 \%)$ \\
\hline PFS rate, 5-year/10-year & $63.5 \% / 50.8 \%$ & $50 \% /$ not reached & $62.2 \% / 49.8 \%$ \\
\hline OS rate, 5-year/10-year & $88.2 \% / 88.2 \%$ & $50 \% /$ not reached & $84.2 \% / 84.2 \%$ \\
\hline
\end{tabular}

*The longest diameter determined on gadolinium-enhanced T1-weighted magnetic resonance imaging. KPS: Karnofsky Performance Status, PFS: progression-free survival, OS: overall survival.

\section{Discussion}

Three outcomes of the present study include, nestin, a neural stem cell marker, exhibits the most robust staining for the diagnosis of PXAs. Second, PXAs demonstrated a low rate of TERTp mutation (7\%). Finally, prognostic factors for PFS, which are not currently well known, were analyzed statistically.

Regarding nestin, a positive correlation between the level of nestin expression and tumor malignancy has been reported in astrocytic gliomas. ${ }^{15,16)}$ However, little is known in PXAs and the present results may be the first observation to disclose the value of nestin staining for the diagnosis of PXAs. This may also imply inherent pathological characteristics of PXAs, currently, a theory exists that PXAs possibly arise from multipotent neuroectodermal precursor cells. ${ }^{1)}$ Nestin is also observed in the mature vascular endothelium. ${ }^{16)}$ In concert with this, PXAs are often positive for vascular endothelial markers, ${ }^{17)}$ such as CD34 $(47 \%)$ in the present series.

The low positive rate of TERTp mutation in PXAs was consistent with previously published results. ${ }^{18)}$ This genetic status was presumed as a molecular feature of PXAs, and may significantly contribute to the practical differential diagnosis between PXAs 
Table 3 Histological and molecular data of patients with PXAs

\begin{tabular}{|c|c|c|c|c|c|c|c|c|c|c|c|c|c|c|c|c|}
\hline Case & $\begin{array}{l}\text { Central } \\
\text { review }\end{array}$ & $\begin{array}{l}\text { Pleomor- } \\
\text { phism }\end{array}$ & $\begin{array}{l}\text { Mitotic } \\
\text { activity }\end{array}$ & $\begin{array}{l}\text { Vascular } \\
\text { proliferation }\end{array}$ & Necrosis & GFAP & S-100 & Nestin & Synapto & NFP & NeuN & CD34 & $\begin{array}{c}\text { IDH1 } \\
\text { R132H }\end{array}$ & $\begin{array}{c}\text { Ki67 } \\
\text { index } \\
(\%)\end{array}$ & $\begin{array}{l}\text { BRAF } \\
\text { status* }\end{array}$ & $\begin{array}{l}\text { TERTp } \\
\text { status* }\end{array}$ \\
\hline 1 & PXA & ++ & - & - & - & $\mathrm{p}$ & $\mathrm{p}$ & $\mathrm{p}$ & $\mathrm{n}$ & $\mathrm{n}$ & $\mathrm{n}$ & $\mathrm{n}$ & $\mathrm{n}$ & 0.2 & & \\
\hline 3 & PXA & ++ & - & - & - & $\mathrm{p}$ & $\mathrm{p}$ & $\mathrm{p}$ & $\mathrm{p}$ & $\mathrm{fp}$ & $\mathrm{n}$ & $\mathrm{fp}$ & $\mathrm{n}$ & 1.8 & V600E & wt \\
\hline 4 & PXA & + & - & - & - & $\mathrm{p}$ & $\mathrm{p}$ & $\mathrm{p}$ & $\mathrm{p}$ & $\mathrm{fp}$ & $\mathrm{n}$ & $\mathrm{n}$ & $\mathrm{n}$ & 3.5 & 599insT & wt \\
\hline 5 & PXA & ++ & - & + & - & $\mathrm{p}$ & $\mathrm{p}$ & $\mathrm{p}$ & $\mathrm{n}$ & $\mathrm{n}$ & $\mathrm{n}$ & $\mathrm{n}$ & $\mathrm{n}$ & 3.7 & & \\
\hline 8 & PXA & ++ & - & - & - & $\mathrm{fp}$ & $\mathrm{p}$ & $\mathrm{p}$ & $\mathrm{fp}$ & $\mathrm{fp}$ & $\mathrm{n}$ & $\mathrm{p}$ & $\mathrm{n}$ & 1.9 & V600E & wt \\
\hline 9 & PXA & ++ & - & - & - & $\mathrm{p}$ & $\mathrm{p}$ & $\mathrm{p}$ & $\mathrm{fp}$ & $\mathrm{n}$ & $\mathrm{n}$ & $\mathrm{n}$ & $\mathrm{n}$ & 1.2 & wt & wt \\
\hline 10 & PXA & + & - & - & - & $\mathrm{p}$ & $\mathrm{p}$ & $\mathrm{p}$ & $\mathrm{p}$ & $\mathrm{n}$ & $\mathrm{n}$ & $\mathrm{fp}$ & $\mathrm{n}$ & 5.2 & V600E & wt \\
\hline 11 & PXA & ++ & - & - & - & $\mathrm{p}$ & $\mathrm{p}$ & $\mathrm{p}$ & $\mathrm{n}$ & $\mathrm{n}$ & $\mathrm{n}$ & $\mathrm{fp}$ & $\mathrm{n}$ & 0.9 & wt & wt \\
\hline 12 & PXA & ++ & - & - & - & $\mathrm{p}$ & $\mathrm{p}$ & $\mathrm{p}$ & $\mathrm{p}$ & $\mathrm{n}$ & $\mathrm{n}$ & $\mathrm{fp}$ & $\mathrm{n}$ & 2.6 & & wt \\
\hline 16 & PXA & ++ & - & - & - & $\mathrm{p}$ & $\mathrm{p}$ & $\mathrm{p}$ & NA & $\mathrm{n}$ & $\mathrm{n}$ & $\mathrm{p}$ & $\mathrm{n}$ & 4 & V600E & wt \\
\hline 17 & PXA & - & - & - & - & $\mathrm{p}$ & $\mathrm{p}$ & $\mathrm{p}$ & $\mathrm{n}$ & NA & $\mathrm{n}$ & $\mathrm{fp}$ & $\mathrm{n}$ & 0.3 & V600E & wt \\
\hline 18 & A-PXA & ++ & + & + & ++ & $\mathrm{p}$ & $\mathrm{fp}$ & $\mathrm{p}$ & $\mathrm{fp}$ & $\mathrm{fp}$ & $\mathrm{n}$ & $\mathrm{n}$ & $\mathrm{n}$ & 47.5 & wt & wt \\
\hline 19 & A-PXA & ++ & + & + & + & $\mathrm{p}$ & $\mathrm{p}$ & $\mathrm{p}$ & $\mathrm{n}$ & $\mathrm{n}$ & $\mathrm{n}$ & $\mathrm{n}$ & $\mathrm{n}$ & 16.7 & wt & $\mathrm{C} 228 \mathrm{~T}$ \\
\hline
\end{tabular}

*The results were not obtained for $B R A F$ from five samples and for TERTp from four samples because of degradation of the genome structure. -: none, +: moderate, ++: marked, fp: focally positive, n: negative, NA: not available, p: positive, PXAs: pleomorphic xanthoastrocytoma, synapto: synaptophysin, wt: wild-type. 
Table 4 Summary of histological and molecular data in the present series

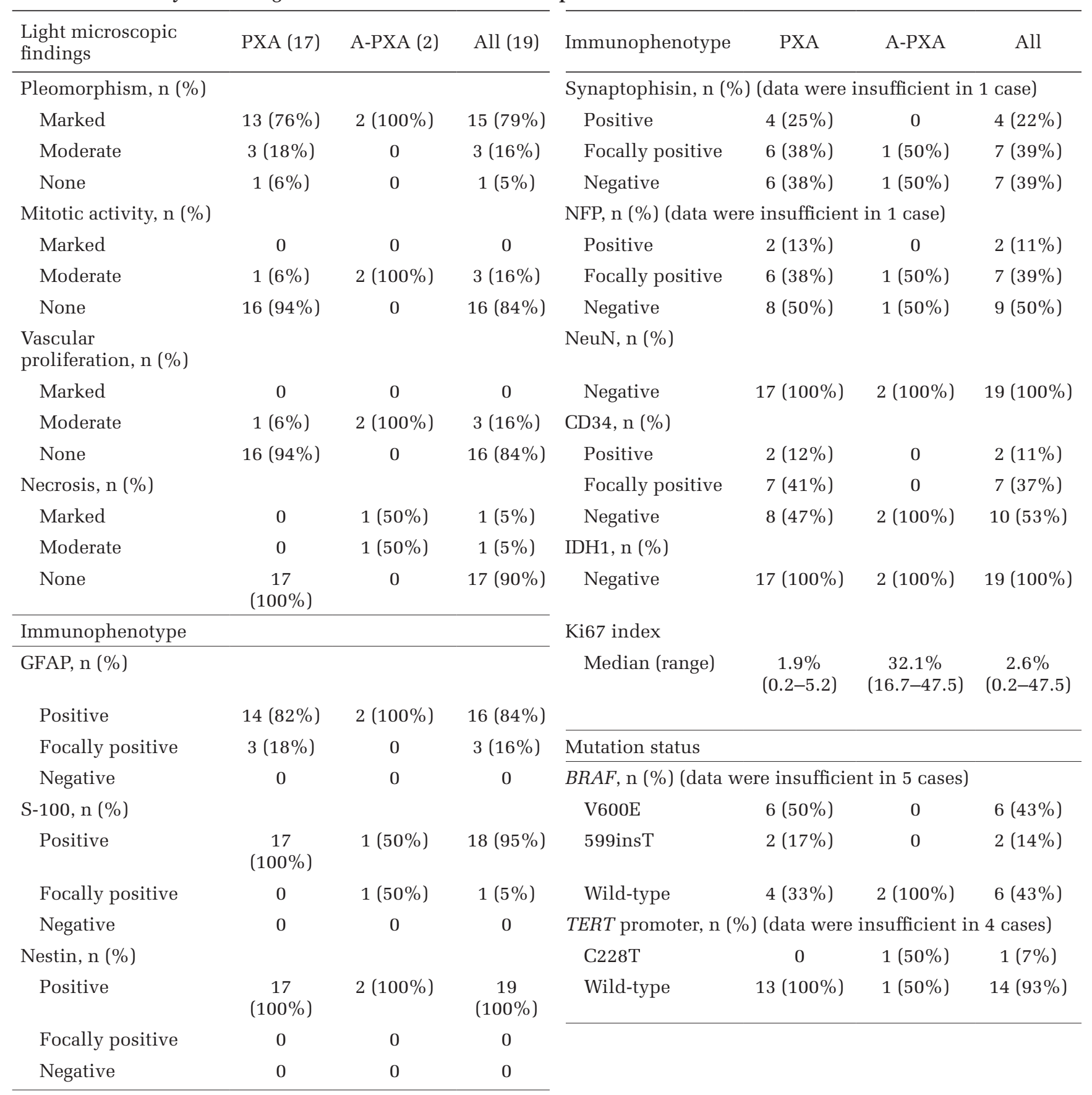

PXA: pleomorphic xanthoastrocytoma.

and GBMs including giant cell glioblastoma (gcGBM) and epithelioid glioblastoma (eGBM). GBMs, IDH-wildtype, and eGBMs show a high frequency of TERTp mutations (71-90\%). ${ }^{3,10,19-21)}$ This enables differentiation from PXAs. Since GBMs, IDH-mutant and gcGBMs, have a low rate of TERTp mutation $(28 \%$ and $25 \%$, respectively). ${ }^{22,23)}$ The differentiation from PXA is therefore not feasible by only TERTp mutation. However, the present and previous studies indicate that $I D H$ mutation is absent in PXAs. ${ }^{4,18,24)}$ In addition, neuronal markers that are often positive in PXAs are negative in gcGBM. ${ }^{25}$ Further, whereas $50 \%-78 \%$ of PXAs present in BRAF V600E mutation, ${ }^{1)}$ the frequency is less than $10 \%$ in IDH-mutant GBM and gcGBM. ${ }^{13)}$ Thus, there is a possibility that the mutation status of TERTp is a significant distinctive element between PXAs and GBMs, as also supported by the results of the present study. 

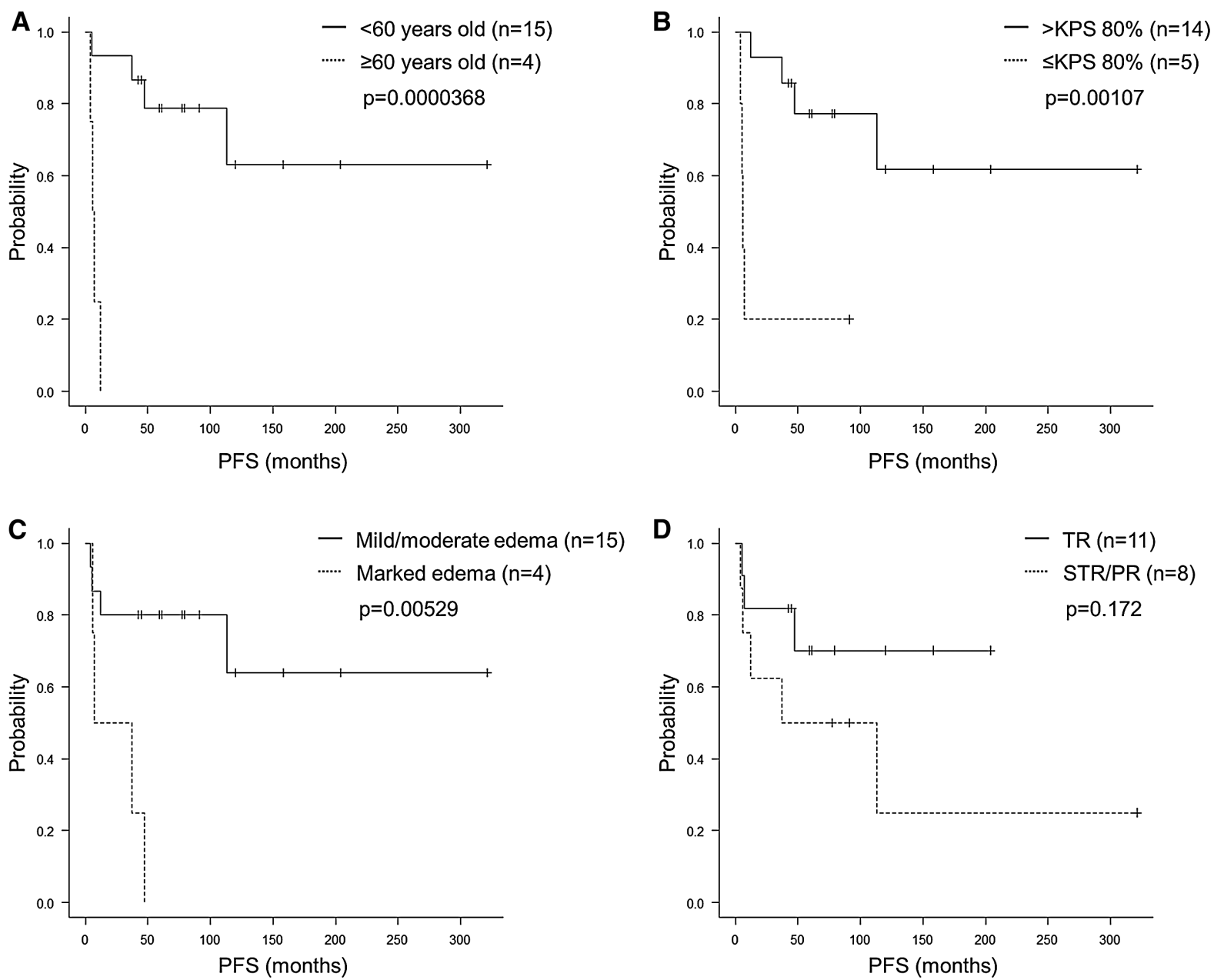

Fig. 1 Representative Kaplan-Meier survival curves for PFS according to age (<60 years vs. $\geq 60$ years) (A), preoperative KPS ( $>\mathbf{8 0} \%$ vs. $\leq \mathbf{8 0} \%$ ) (B), peritumoral edema on MRI (mild to moderate vs. marked) (C), and extent of resection (TR vs. STR and PR) (D). KPS: Karnofsky performance status, PFS: progression-free survival, PR: partial resection, STR: subtotal resection, TR: total resection.

The last point concerns the prognostic factors of PXAs. The present survival analyses demonstrated that advanced age, poor preoperative KPS, and marked perifocal edema were significantly associated with a shorter PFS. These results are consistent with previous studies suggesting that higher age ${ }^{26)}$ and marked perifocal edema ${ }^{27)}$ are associated with worse PFS in PXAs. The KPS has not been well investigated in available literature and the present results may provide a new insight.

Limitations of the present study include a small number of patients and retrospective nature that leads to inherent biases. Nevertheless, this study may help clinicians make proper diagnoses and prognostic prediction, and encourage a larger clinical study.
The present study analyzed 19 patients with PXA retrospectively gathered from seven universities of the Tohoku district of Japan over a 21-year period. In molecular features, PXA was characterized by positive nestin and few TERTp mutation. Neuronal markers may help diagnosis. Several prognostic factors were identified on univariate analysis, but patient age and preoperative KPS were the strongest factors. A further clinical study may be required.

\section{Acknowledgments}

The authors would like to sincerely thank Dr. Masaya Oda, Dr. Ryuta Saito, Dr. Yuichi Sato, and Dr. Kaori Sakurada for their constructive suggestions for this study. 
The research was supported by Research Grant of Japan Brain Foundation, 2014.

\section{Conflicts of Interest Disclosure}

All authors report no conflicts of interest concerning this article.

\section{References}

1) Louis DN, Ohgaki H, Wiestler OD, Cavenee WK (Eds): World Health Organization classification of tumours of the central nervous system revised 4th, Lyon: International Agency for Research on Cancer, 2016

2) Giannini C, Scheithauer BW, Burger PC, et al.: Pleomorphic xanthoastrocytoma: what do we really know about it? Cancer 85: 2033-2045, 1999

3) Korshunov A, Chavez L, Sharma T, et al.: Epithelioid glioblastomas stratify into established diagnostic subsets upon integrated molecular analysis. Brain Pathol 28: 656-662, 2017

4) Ida CM, Rodriguez FJ, Burger PC, et al.: Pleomorphic xanthoastrocytoma: natural history and long-term follow-up. Brain Pathol 25: 575-586, 2015

5) Giannini C, Scheithauer BW, Lopes MB, Hirose T, Kros JM, VandenBerg SR: Immunophenotype of pleomorphic xanthoastrocytoma. Am J Surg Pathol 26: 479-485, 2002

6) Powell SZ, Yachnis AT, Rorke LB, Rojiani AM, Eskin TA: Divergent differentiation in pleomorphic xanthoastrocytoma. Evidence for a neuronal element and possible relationship to ganglion cell tumors. Am J Surg Pathol 20: 80-85, 1996

7) Tabouret E, Bequet C, Denicolaï E, et al.: BRAF mutation and anaplasia may be predictive factors of progression-free survival in adult pleomorphic xanthoastrocytoma. Eur J Surg Oncol 41: 1685-1690, 2015

8) Nakazato Y, Ishizeki J, Takahashi K, Yamaguchi H, Kamei T, Mori T: Localization of S-100 protein and glial fibrillary acidic protein-related antigen in pleomorphic adenoma of the salivary glands. Lab Invest 46: 621-626, 1982

9) Tanaka GNY: Automatic quantification of the MIB-1 immunoreactivity in brain tumors. In: Watanabe K, et al. (eds): Developments in Neuroscience Proceedings of the 3rd International Mt Bandai Symposium for Neuroscience and the 4th Pan-Pacific Neurosurgery Congress. 1259: 15-19, 2004

10) Nakajima N, Nobusawa $S$, Nakata $S$, et al.: BRAF V600E, TERT promoter mutations and CDKN2A/B homozygous deletions are frequent in epithelioid glioblastomas: a histological and molecular analysis focusing on intratumoral heterogeneity. Brain Pathol 28: 663-673, 2017
11) Nobusawa $S$, Lachuer J, Wierinckx A, et al.: Intratumoral patterns of genomic imbalance in glioblastomas. Brain Pathol 20: 936-944, 2010

12) Gessi M, van de Nes J, Griewank K, et al.: Absence of TERT promoter mutations in primary melanocytic tumours of the central nervous system. Neuropathol Appl Neurobiol 40: 794-797, 2014

13) Schindler G, Capper D, Meyer J, et al.: Analysis of BRAF V600E mutation in 1,320 nervous system tumors reveals high mutation frequencies in pleomorphic xanthoastrocytoma, ganglioglioma and extra-cerebellar pilocytic astrocytoma. Acta Neuropathol 121: 397405, 2011

14) Kanda Y: Investigation of the freely available easy-touse software 'EZR' for medical statistics. Bone Marrow Transplant 48: 452-458, 2013

15) Brehar FM, Arsene D, Brinduse LA, Gorgan MR: Immunohistochemical analysis of GFAP- $\delta$ and nestin in cerebral astrocytomas. Brain Tumor Pathol 32: 90-98, 2015

16) Tomita T, Akimoto J, Haraoka J, Kudo M: Clinicopathological significance of expression of nestin, a neural stem/progenitor cell marker, in human glioma tissue. Brain Tumor Pathol 31: 162-171, 2014

17) Koelsche C, Sahm F, Wöhrer A, et al.: BRAFmutated pleomorphic xanthoastrocytoma is associated with temporal location, reticulin fiber deposition and CD34 expression. Brain Pathol 24: 221-229, 2014

18) Ma $C$, Feng R, Chen $H$, et al.: BRAF V600E, TERT, and IDH2 mutations in pleomorphic xanthoastrocytoma: observations from a large case-series study. World Neurosurg 120: e1225-e1233, 2018

19) Eckel-Passow JE, Lachance DH, Molinaro AM, et al.: Glioma groups based on 1p/19q, IDH, and TERT promoter mutations in tumors. N Engl J Med 372: 24992508, 2015

20) Killela PJ, Pirozzi CJ, Healy P, et al.: Mutations in IDH1, IDH2, and in the TERT promoter define clinically distinct subgroups of adult malignant gliomas. Oncotarget 5: 1515-1525, 2014

21) Killela PJ, Reitman ZJ, Jiao Y, et al.: TERT promoter mutations occur frequently in gliomas and a subset of tumors derived from cells with low rates of selfrenewal. Proc Natl Acad Sci USA 110: 6021-6026, 2013

22) Nonoguchi N, Ohta T, Oh JE, Kim YH, Kleihues P, Ohgaki H: TERT promoter mutations in primary and secondary glioblastomas. Acta Neuropathol 126: 931-937, 2013

23) Oh JE, Ohta T, Nonoguchi N, et al.: Genetic alterations in gliosarcoma and giant cell glioblastoma. Brain Pathol 26: 517-522, 2016

24) Balss J, Meyer J, Mueller W, Korshunov A, Hartmann C, von Deimling A: Analysis of the IDH1 codon 132 mutation in brain tumors. Acta Neuropathol 116: 597-602, 2008

25) Martinez-Diaz H, Kleinschmidt-DeMasters BK, Powell SZ, Yachnis AT: Giant cell glioblastoma and pleomorphic xanthoastrocytoma show different 
immunohistochemical profiles for neuronal antigens and p53 but share reactivity for class III beta-tubulin. Arch Pathol Lab Med 127: 1187-1191, 2003

26) Mallick S, Benson R, Melgandi W, Giridhar P, Rath GK: Grade II pleomorphic xanthoastrocytoma, a metaanalysis of data from previously reported 167 cases. J Clin Neurosci 54: 57-32, 2018

27) Lim S, Kim JH, Kim SA, Park ES, Ra YS, Kim CJ: Prognostic factors and therapeutic outcomes in 22 patients with pleomorphic xanthoastrocytoma. J Korean Neurosurg Soc 53: 281-287, 2013

Corresponding author: Takahiro Ono, MD, PhD

Department of Neurosurgery, Akita University Graduate School of Medicine, 1-1-1 Hondo, Akita, Akita 010-8543, Japan.

e-mail: t.ono@med.akita-u.ac.jp 